\title{
Estimating the abundance of benthic invertebrates: a comparison of procedures and variability between observers
}

\author{
Lisandro Benedetti-Cecchi*, Laura Airoldi, Marco Abbiati, Francesco Cinelli
}

Dipartimento di Scienze dell'Ambiente e del Territorio, Università di Pisa, Via A. Volta 6, I-56126 Pisa, Italy

\begin{abstract}
Different procedures for underwater sampling of epifaunal organisms were compared for their robustness to bias due to observers and precision using multifactornal sampling designs. Variability among 3 observers was tested in relation to: (1) the method employed to estimate the percent cover of organisms (visual vs point-intercept technique); (2) the size of quadrats $(50 \times 50 \mathrm{vs} 20 \times 20 \mathrm{~cm}$ ); (3) stress (sampling at the beginning vs the end of the dive), and (4) random factors that were likely to change from dive to dive. Precision was expressed in terms of standard errors (over 3 replicates) obtained with each method and size. Two cnidarians (Astroides calycularis and Leptosammia pruvoti) and 2 sponges (Petrosia ficiformis and Geodia cydonium) were considered in this study because of their abundance at the study site (a submarine cave). Much of the variability was related to significant differences between observers that changed from dive to dive for estimates of the cover of $A$. calycularis, and from dive to dive and with method for $L$. pruvoti. The small quadrats were more precise than the large ones when used to estimate the percent cover of $A$ calycularis and $L$. pruvoti, irrespective of method. In contrast, for $P$. ficiformis the small quadrats were more precise if sampled with the visual method, while the reverse occurred for the large quadrats. A trend toward a greater precision of the large quadrats sampled with the visual method was evident for $G$. cydonium, although no significant effects were found. Pilot studies and cost-benefit analyses were also used to determine the optimal allocation of resources (time) for sampling epifaunal organisms at different spatial scales in the cave, for each method and size of quadrats. The small units in conjunction with the visual method were most efficient. This procedure offered the best compromise between repeatability among observers, precision and maximization of replication for a fixed amount of resources. The large quadrats in conjunction with the visual method were probably more adequate for $G$. cydonium, given the apparent greater precision provided by this procedure for the large sponge. Caution is recommended in employing different researchers working on the same sampling project in extreme environments, at least before divergence among observers to changing environmental conditions is accounted for.
\end{abstract}

KEY WORDS: Design of sampling - Robustness - Precision - Efficiency - Submarine caves - Invertebrates Cost-benefit analyses

\section{INTRODUCTION}

Natural populations must be sampled in order to determine patterns of species distribution or the outcome of field experiments. Because of its central role in ecological research, there has been much theoretical and empirical concern about the methodology and the design of sampling (Green 1979, Greig-Smith 1983,

•E-mail: bencecc@discat.unipi.it
Andrew \& Mapstone 1987). Procedures may vary according to the questions being asked, the complexity of the habitat under investigation, the spatial arrangement of the organisms and other features of the environment. In addition, logistic and economic considerations always impose constraints on the execution of sampling programs. Different methods may be compared in terms of accuracy and precision, and pilot studies have proved to be very helpful in determining the most efficient allocation of resources (Kennelly \& Underwood 1984, 1985). 
The way organisms are quantified, the size of the sampling units and the number of replicates all affect the accuracy and precision of a given method and dictate the efficiency of a sampling program. Marine benthic ecologists often quantify the abundance of plants and sessile animals in terms of surface cover. Among the possible methods that can be used to obtain such estimates there are: (1) the point-intercept technique by means of grids of dots (either at fixed or random positions) scored directly in the field (e.g. Meese \& Tomich 1992); (2) the point-intercept technique with estimates obtained by photographing or video recording the plots and projecting the images on a grid of dots in the laboratory (Littler \& Littler 1985, Leonard \& Clark 1993, Roberts et al. 1994); (3) visual estimates of cover (Dayton 1975, Dethier 1984, Meese \& Tomich 1992, Dethier et al. 1993), and (4) electronic digitizing of images (Meese \& Tomich 1992, Whorff \& Griffing 1992). Studies have addressed questions about the relative precision and accuracy of some of these methods and have compared their robustness to bias due to observers (Foster et al. 1991, Meese \& Tomich 1992, Dethier et al. 1993). There are advantages and disadvantages associated with each of these methods. For example, photographic and video techniques provide permanent records of a particular situation and reduce the time spent in the field, but cover estimates may be less accurate and precise than those obtained by direct inspection of the plots (Foster et al. 1991, Leonard \& Clark 1993). Visual sampling is not a probabilistic method and can be subjective, but Dethier et al. (1993) found it more accurate, precise and rapid than the point-intercept technique with random points. These authors also found that visual estimates were less subject to bias due to observers than random points. Opposite conclusions were drawn by Meese \& Tomich (1992) for estimates of cover of the red alga Endocladia muricata and for the aggregate cover of macroalgae in their plots. Inconsistency in results among the 2 studies might have arisen, in part, because of variability in species composition among the 2 assemblages, variability among observers and slight differences in the technique (Dethier et al. 1993 used small subdivisions in quadrats to help scoring). Perhaps the message from these studies is that no approach is generally valid, and the adequacy of a given method should be evaluated in any particular situation.

This study was done in a submarine cave (Grotta Azzurra, Capo Palinuro, Italy), where multidisciplinary investigations are carried out on shallow-water thermal vents. Little attention has been paid to methods for sampling benthic fauna in submarine caves, and in most previous studies sampling is unreplicated (Cinelli et al. 1977, Balduzzi et al. 1985, Gili et al. 1986). These systems provide variable environmental conditions affecting the distribution of organisms and the performance of observers. Absence of sunlight and turbidity may interfere with scoring of plots, and the closed environment may cause additional stress to the divers. Our aim was to compare different procedures commonly used on rocky shores for their robustness to bias due to observers and precision. In addition, pilot studies were done to determine spatial variation in the abundance of organisms between positions at 3 different distances from the entrance to the innermost part of the cave and among areas within each position. Cost-benefit analyses were done to determine optimal number of replicates and replicated areas for each method. Thus, the most adequate procedure of sampling was identified as the best compromise between repeatability among observers, precision and maximization of replication given a fixed amount of resources.

\section{METHODS}

Study site. This study was done in May 1994 in the Grotta Azzurra Cave of Capo Palinuro, on the southwest coast of Italy (western Mediterranean). This is a large cavity of about $120000 \mathrm{~m}^{3}$ in volume and with a maximum depth of about $30 \mathrm{~m}$ (Alvisi et al. 1994). Below the main entrance, the cave opens in a wide chamber (also known as Central Hall) accessible by boat from the surface, extending to a secondary underwater entrance. Here light is reduced but still present, and currents create water exchanges with the open sea. A smaller inner hall (hereafter Snow Hall) opens on the left wall of Central Hall with respect to the main entrance. Snow Hall is shallower (about $15 \mathrm{~m}$ ), completely dark and has a reduced hydrodynamic regime. A main feature of this part of the cave is the occurrence of sulphur water springs originating an oxic-anoxic interface at about $9 \mathrm{~m}$ depth, with the thermal water stratified above the sea water. Dense mats of sulphur oxidising bacteria are present on the rocky surfaces of the vault and the sides above the chemocline. In contrast, all the hard substrata below the chemocline support a rich assemblage of epifaunal organisms. The most conspicuous organisms in these areas are sponges (particularly Geodia cydonium and Petrosia ficiformis) and cnidarians (Astroides calycularis and Leptosammia pruvoti). A detailed description of patterns of distribution of these organisms will be reported in a separate paper. Further information on the faunal assemblages of this cave can be found in Southward et al. (1996).

Comparison of methods. This study was designed to compare percent cover estimates of sponges and cnidarians obtained with different methods of sam- 
pling and different sizes of the sampling units, for their robustness to bias due to observers and precision. Sampling was done on the outer part of the vault of Snow Hall, where the complexity of the assemblage was high (authors' unpubl. data). Three divers participated in the sampling program. Twelve dives were done, and 6 plots, distributed at random on the vault, were sampled by all the observers during each dive. Different plots were located during different dives. Each time, 3 of these plots were sampled with plexiglass sheets supporting 100 evenly spaced dots, while in the other 3 quadrats percent cover values were obtained by visual estimates. In this case a plexiglass sheet divided into 25 small quadrats was used, and a score from 0 to $4 \%$ was given to each species in each small square (Dethier et al. 1993). For each method, quadrats of 2 different sizes were used: 0.25 and $0.04 \mathrm{~m}^{2}$. Sampling was done with the larger quadrat for 6 dives (chosen at random) and with the smaller one in the other 6 . In addition, to account for differences in estimates due to stress, sampling was done at 2 different times (again assigned at random to dives): at the beginning of the dive or after some time (usually $45 \mathrm{~min}$ ) spent working on something else. In summary, there were 3 replicated dives for each combination of sample size $\times$ stress and 2 different methods employed in each dive. Three replicated quadrats were sampled with each method by all the observers (Table 1).

These data were analysed using repeated-measures analysis of variance (ANOVA), with dives and plots as random factors and the other variables considered fixed. Observers were fixed (but see 'Discussion') because they had different experiences with nondestructive sampling, ranging from high training (5 yr) to medium training ( $2.5 \mathrm{yr}$ ) and no training. Dives were nested within each combination of stress and size of quadrats, while method (visual vs point-intercept) was

Table 1 . Scheme of the sampling design used to compare different sizes of sampling units $(50 \times 50 \mathrm{vs} 20 \times 20 \mathrm{~cm}$ ) and different methods (visual vs point-intercept) for ther repeatibility among observers and precision. Six plots were randomly sampled during each dive with quadrats of a particular size just at the beginning (low stress) or at the end (high stress) of the dive. There were 3 replicate plots for each of the 2 methods and every plot was sampled by the 3 observers

\begin{tabular}{|clrlrc|}
\hline $\begin{array}{c}\text { Size of } \\
\text { quadrats }(\mathrm{cm})\end{array}$ & Stress & Dive & $\begin{array}{l}\text { Method of } \\
\text { sampling }\end{array}$ & $\begin{array}{c}\text { Replicated } \\
\text { plots }\end{array}$ & $\begin{array}{c}\text { Ob- } \\
\text { servers }\end{array}$ \\
\hline $50 \times 50$ & High & $1,2 \& 3$ & Visual & $1,2 \& 3$ & $1,2 \& 3$ \\
$50 \times 50$ & High & $1,2 \& 3$ & Point-intercept & $1,2 \& 3$ & $1,2 \& 3$ \\
$50 \times 50$ & Low & $1,2 \& 3$ & Visual & $1,2 \& 3$ & $1,2 \& 3$ \\
$50 \times 50$ & Low & $1,2 \& 3$ & Point-intercept & $1,2 \& 3$ & $1,2 \& 3$ \\
$20 \times 20$ & High & $1,2 \& 3$ & Visual & $1,2 \& 3$ & $1,2 \& 3$ \\
$20 \times 20$ & High & $1,2 \& 3$ & Point-intercept & $1,2 \& 3$ & $1,2 \& 3$ \\
$20 \times 20$ & Low & $1,2 \& 3$ & Visual & $1,2 \& 3$ & $1,2 \& 3$ \\
$20 \times 20$ & Low & $1,2 \& 3$ & Point-intercept & $1,2 \& 3$ & $1,2 \& 3$ \\
\hline
\end{tabular}

orthogonal to these factors. The assumption of 'compound symmetry' was tested by the sphericity test using Mauchly's criterion (Crowder \& Hand 1990).

Interactions between observers and the other terms provided tests for the robustness of the different methods to bias due to observers. A central assumption of these analyses is that the differences among observers are constant in magnitude and direction from plot to plot (Winer 1971). In other words the observer $\times$ plot interactions should provide an estimation of the residual variance. If this assumption is violated, there are no hypotheses related to the other sources of variation in the model (Underwood 1981). Unfortunately, there is no direct way to test for this assumption with non-independent data. However, results from pilot studies in the same habitat and on the same species (see below) provided independent estimates of residual mean squares (for each method and size of quadrat) similar to, or higher than, those obtained with the repeated-measures design (compare Tables 2 \& 4 for Astroides calycularis). This suggests that the observer $x$ plot interactions were probably negligible. In addition, it should be stressed that there is no interest at all in testing for these interactions, as no plot will be sampled by more than 1 observer during the real sampling (i.e. in any future sampling program).

The relative precision of the different methods and size of quadrats was assessed by comparing the standard errors (Andrew \& Mapstone 1987) calculated for each observer from the 3 replicated plots sampled during each dive with each of the 2 methods. Two-way ANOVAs were used for these comparisons. Variability among dives and levels of stress were not considered in these analyses, as it is likely that sampling activity will encompass a wide range of environmental conditions in any real program. Thus, the main interest here is in the overall performance of each procedure.

Pilot studies. Pilot studies were done to determine spatial variation in the abundance of epifauna species between 3 positions from the entrance towards the innermost part of Snow Hall (10 to $20 \mathrm{~m}$ apart), and among areas within each position ( 4 to $5 \mathrm{~m}$ apart). The relative abundance of sponges and cnidarians was determined by a single observer for each method and size of quadrats. Two areas ( 3 to $4 \mathrm{~m}^{2}$ each) were located at each position, and 3 replicate plots were sampled in each area.

Nested ANOVAs and cost-benefit analyses were used to determine the optimal number of replicate plots and areas for each method. Standard procedures (Snedecor \& Cochran 
1967. Winer 1971, Underwood 1981) were used for calculations. In particular, the number of replicate plots per area $(n)$ was determined as:

$$
n=\sqrt{\frac{S_{e}^{2} \cdot C_{a}}{S_{A(P)}^{2} \cdot C_{r}}} .
$$

where $S_{\mathrm{e}}{ }^{2}$ is the estimated variance among replicates, $C_{a}$ is the cost (in terms of time) per area, $S_{A(P)}^{2}$ is the estimated variance among areas and $C_{r}$ is the cost (in terms of time) per replicate. The variances for estimated means were determined from the appropriate mean squares resulting from the nested ANOVAs (Winer 1971, Underwood 1981). The optimal number of areas $(a)$ was determined as:

$$
a=\frac{\text { Cost of each position }}{n C_{r}+C_{a}}
$$

\section{RESULTS}

\section{Comparison of methods}

An illustrative repeated-measures ANOVA is reported in Table 2 for estimates of the cover of Astroides calycularis. Observers produced different estimates of the mean abundance of this cnidarian that changed significantly from dive to dive. Differences ranged from a minimum of $0.7 \%$ to a maximum of $14.3 \%$. Also, variability between observers changed in relation to the method employed, as indicated by the significant interaction observer $x$ method. However, although the rank of divers changed with method, overall differences in the estimates of cover were very similar $(2 \%$ with the point-intercept technique and $3.2 \%$ with the visual method). No other source of variation was significant in this analysis.

Variability also occurred for estimates of the mean abundance of Leptosammia pruvoti. In this case the second-order interaction observer $x$ method $x$ dives (nested in each combination of size of quadrat $x$ stress) was significant $\left(F_{16,96}=1.9, \mathrm{p}=0.0296\right)$. Differences from dive to dive ranged from 0.7 to $7 \%$ with the pointintercept technique and from 0.7 to $11 \%$ with the visual method. In addition, the large quadrats produced greater mean estımates of cover than the small sampling units for this species $\left(F_{1.8}=17, p=0.0033\right)$.

Estimates of the mean percent cover of the sponges Petrosia ficiformis and Geodia cydonium were not affected by observers nor by interactions between obervers and any other term in the model. Significant effects due to the size of quadrats were found for $P$. ficiformis $\left(F_{1,8}=5.5, \mathrm{p}=0.0478\right)$, with the large units producing higher means. The data for G. cydonium did not conform to the assumption of 'compound symmetry' (Mauchly's test: $\mathrm{W}=0.869, \chi^{2}=6.6$, $\mathrm{df}=2, p=0.0369$ ), but, since none of the effects was significant, this did not compromise the interpretation of the analysis

The small quadrats were more precise than the large ones when used to estimate the percent cover of Astroides calycularis and Leptosammia pruvoti, irrespective of the method employed (Fig. 1). These differences were significant in both cases (Table 3). In particular, the highly significant effect observed for A. calycularis makes the result robust to the slight heterogeneity of variances revealed by Cochran's $C$-test $\left(C_{\text {crit }}=0.43\right)$. In contrast, a significant interaction between method and size was observed for Petrosia ficiformis, the precision of the method depending upon the size of the quadrat being sampled (Table 3). In this case the small quadrats were more precise if sampled with the visual method, while the reverse occurred for the large quadrats (Fig. 1, Table 3). 


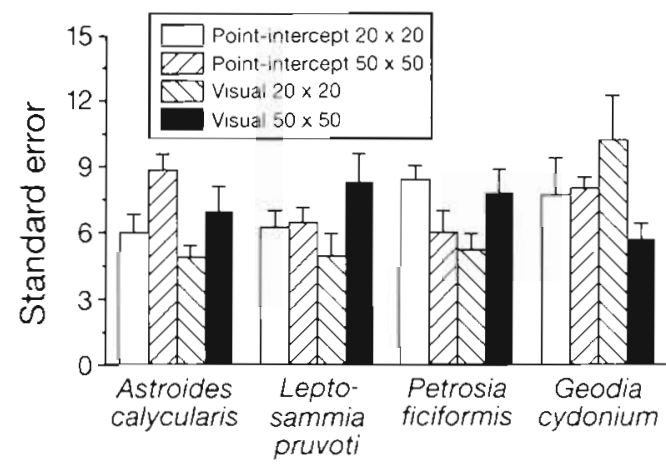

Fig. 1 Precision of estimates of the coverage of sponges and cnidarians sampled with different methods and using quadrats of different size. Plotted values are mean standard errors ( $+1 \mathrm{SE}, \mathrm{n}=18)$ which are inversely related to precision

Finally, estimates of percent cover of Geodia cydonium were not affected by the size of quadrats nor by the method employed (Table 3), although a trend toward a greater precision of the large units when sampled with the visual method was evident (Fig. 1).

\section{Pilot studies}

Data on the spatial distribution of a given species were analysed independently for each method and size of sampling unit. There was considerable variability in the distribution of sponges and cnidarians among areas within each position from the entrance of Snow Hall. Significant differences were found for all organisms, but not all methods and quadrats produced the same results (Table 4). For example, the pointintercept technique in conjunction with the large quadrats produced significant effects for all species but Leptosammia pruvoti. In contrast, no effect was detected using quadrats of the same size as before but using the visual method instead (Table 4). Units of small size yielded significant differences among areas for $L$. pruvoti and Petrosia ficiformis when sampled with the point-intercept technique, and for Astroides calycularis and Geodia cydonium when used in conjunction with the visual method (Table 4). Note that variances were heterogeneous for $G$. cydonium in 2 out of 4 analyses (Table 4 ).

Results of cost-benefit analyses are summarized in Table 5 for each species, method of sampling and size of quadrats. The cost per replicate plot (i.e. the time needed to sample a quadrat) was determined during the previous sampling program for each procedure. On average, 2 min were necessary to sample a plot of $20 \times$ $20 \mathrm{~cm}$ with the point-intercept technique, $1.8 \mathrm{~min}$ for a plot of the same size but with the visual method, $3.5 \mathrm{~min}$ for a quadrat of $50 \times 50 \mathrm{~cm}$ with the pointintercept technique, and $2.3 \mathrm{~min}$ for a large quadrat with the visual method. The cost per area (i.e. the cost to manoeuvre among areas) was 1 min. The optimal number of replicate plots per area (determined from Eq. 1) was in most cases less than 1 and always less than 2 . This resulted because the variability among areas was large, in agreement with the results of more extensive sampling programs in the same habitat (Benedetti-Cecchi et al. unpubl.), and $C_{a}$ was always lower than $C_{r}$. To provide a minimum of replication in each area, we set the number of replicate plots at 2 for any method and size (Table 5). Increasing the number of plots also enhances protection from possible overestimations of $S_{A(\rho)}^{2}$ due to the low number of areas in each position.

Because of logistic constraints and according to our previous experience, the total time available to sample this cave in the future (considering all 3 positions) cannot exceed $120 \mathrm{~min}$ per field trip. Thus, $40 \mathrm{~min}$ will be available for each position. From Eq. (2) and using the optimal number of replicate plots, the optimal number of replicate areas for each position was determined. The anticipated standard errors are also reported (Table 5). As a result, the small quadrats in conjunction with the visual method will maximize replication of areas in any future sampling program on this cave.

Table 3. Results of ANOVAs on the effects of method and size of the sampling unit on the precision of estimates (standard errors) of coverage for sponges and cnidarians. Bold numbers indicate significance at $p<0.05$

\begin{tabular}{|c|c|c|c|c|c|c|c|c|c|c|c|c|c|}
\hline \multirow{3}{*}{$\begin{array}{l}\text { Source of } \\
\text { variation }\end{array}$} & \multirow[t]{3}{*}{ df } & \multicolumn{12}{|c|}{ Species } \\
\hline & & \multicolumn{3}{|c|}{ Astroides calycularis } & \multicolumn{3}{|c|}{ Leptosammia pruvoti } & \multicolumn{3}{|c|}{ Petrosia ficiformis } & \multicolumn{3}{|c|}{ Geodia cydonium } \\
\hline & & MS & $F$ & $\mathrm{p}$ & $\mathrm{MS}$ & $F$ & $\mathrm{p}$ & MS & $F$ & $\mathrm{p}$ & MS & $F$ & $\mathrm{p}$ \\
\hline Method & 1 & 1.491 & 3.4 & 0.068 & 0.021 & 0.0 & 0.845 & 8.562 & 0.6 & 0.433 & 0.371 & 0.5 & 0.469 \\
\hline Size & 1 & 3.128 & 7.2 & 0.009 & 2.218 & 4.1 & 0.046 & 0.129 & 0.0 & 0.923 & 0.142 & 0.2 & 0.653 \\
\hline Method $\times$ Size & 1 & 0.262 & 0.6 & 0.440 & 1.635 & 3.0 & 0.086 & 111.840 & 8.1 & 0.006 & 1.815 & 2.6 & 0.111 \\
\hline Residual & 68 & 0.433 & & & 0.537 & & & 13.75 & & & 0.698 & & \\
\hline \multirow{2}{*}{\multicolumn{2}{|c|}{$\begin{array}{l}\text { Transformation } \\
\text { Cochran's C-test }\end{array}$}} & \multirow{2}{*}{\multicolumn{3}{|c|}{$\begin{array}{c}\text { Square root } \\
C=0.45, p<0.05\end{array}$}} & \multirow{2}{*}{\multicolumn{3}{|c|}{$\begin{array}{c}\text { Square root } \\
C=0.37, p>0.05\end{array}$}} & \multicolumn{3}{|c|}{ None } & \multicolumn{3}{|c|}{$\ln$} \\
\hline & & & & & & & & $C=C$ & $0.37, \mathrm{p}$ & $>0.05$ & $C=0$ & $.47, \mathrm{~F}$ & $<0.05$ \\
\hline
\end{tabular}


Table 4. Results of nested ANOVAs on the effects of positions and areas within positions for each species, method of sampling and size of quadrats. Data entries are percent coverage values. Bold numbers indicate significance at $p<0.05$

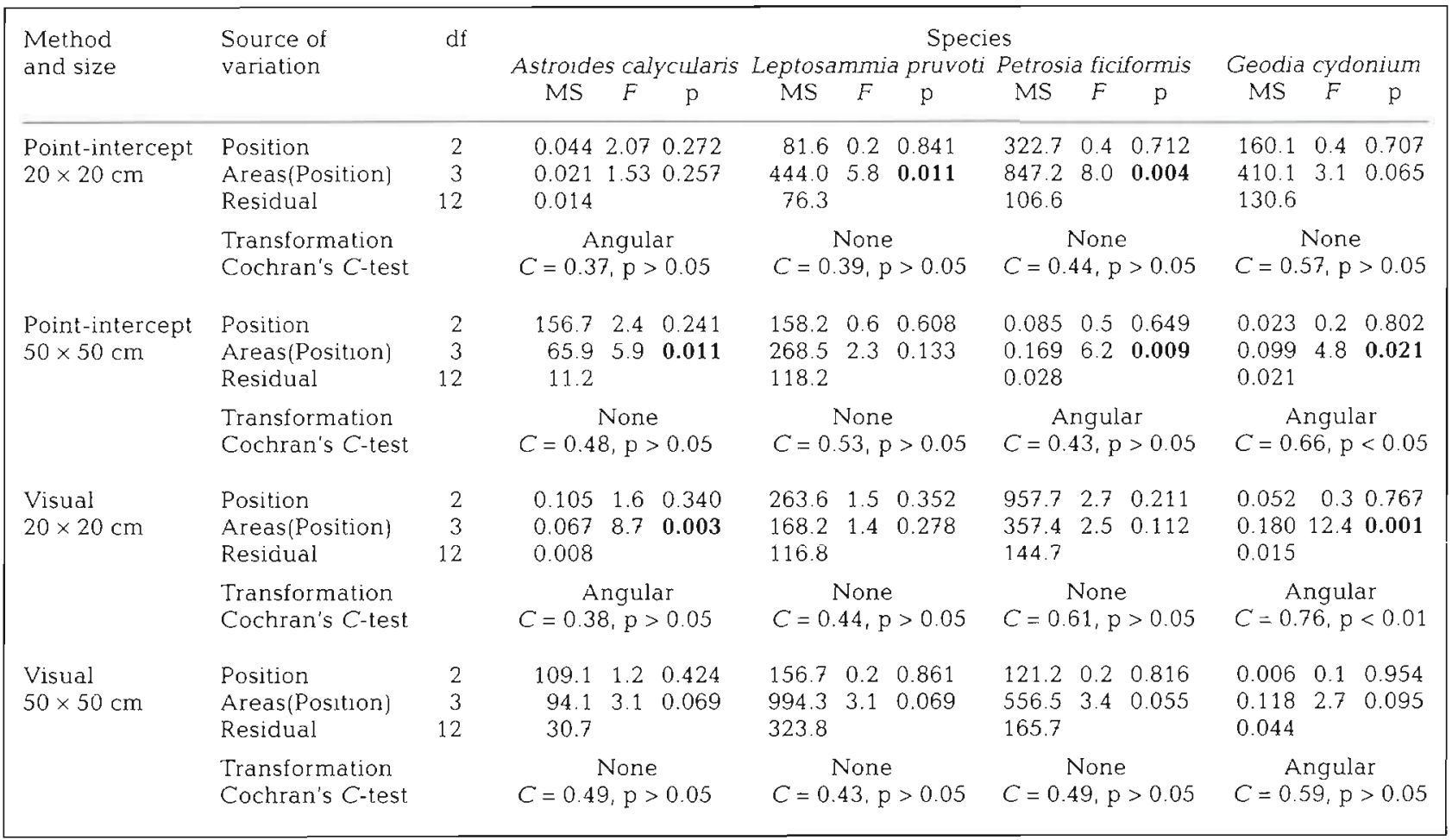

Table 5. Summary of cost-benefit analyses for sampling percent coverage of sponges and cnidarians in a submarine cave

\begin{tabular}{|c|c|c|c|c|c|c|c|c|c|c|c|c|c|c|c|}
\hline \multirow{3}{*}{$\begin{array}{l}\text { Method: } \\
\text { Size: }\end{array}$} & \multicolumn{4}{|c|}{ Astroides calyculanis } & \multicolumn{3}{|c|}{ Leptosammia pruvoti } & \multicolumn{4}{|c|}{$\begin{array}{l}\text { Species } \\
\quad \text { Petrosia ficiformis }\end{array}$} & \multicolumn{4}{|c|}{ Geodia cydonium } \\
\hline & \multicolumn{2}{|c|}{ Point } & \multicolumn{2}{|c|}{ Visual } & \multicolumn{3}{|c|}{ Point Visual } & \multicolumn{2}{|c|}{ Point } & \multicolumn{2}{|c|}{ Visual } & \multicolumn{4}{|c|}{ Point Visual } \\
\hline & $\infty^{+}$ & $\vartheta^{+}$ & $0^{+}$ & $v^{+}$ & $\infty^{+} \vartheta^{+}$ & $s^{+}$ & $\stackrel{p}{\varphi^{+}}$ & $\infty^{+}$ & $\vartheta^{+}$ & $5^{+}$ & $i^{+}$ & $5^{+}$ & $\vartheta^{+}$ & $5^{+}$ & $\theta^{+}$ \\
\hline $\begin{array}{l}\text { Variance among } \\
\text { replicates }\end{array}$ & 11.2 & 0.014 & 30.7 & 0.008 & 118.276 .3 & 323.8 & 116.8 & 0.028 & 106.6 & 165.7 & 144.7 & 0.021 & 130.6 & 0.044 & 0.015 \\
\hline $\begin{array}{l}\text { Variance among } \\
\text { areas }\end{array}$ & 18.2 & 0.002 & 21.1 & 0.020 & 50.1122 .6 & 223.5 & 17.1 & 0.047 & 246.9 & 130.3 & 70.9 & 0.026 & 93.2 & 0.025 & 0.055 \\
\hline $\begin{array}{l}\text { Optimal number } \\
\text { of replicates }\end{array}$ & 2 & 2 & 2 & 2 & 2 & 2 & 2 & 2 & 2 & 2 & 2 & 2 & 2 & 2 & 2 \\
\hline $\begin{array}{l}\text { Optimal number } \\
\text { of areas }\end{array}$ & 5 & 8 & 7 & 9 & 8 & 7 & 9 & 5 & 8 & 7 & 9 & 5 & 8 & 7 & 9 \\
\hline Estimated SE & 2.2 & 0.034 & 2.3 & 0.05 & $4.7 \quad 4.5$ & 7.4 & 2.9 & 0.110 & 6.1 & 5.5 & 4.0 & 0.085 & 4.5 & 0.082 & 0.083 \\
\hline
\end{tabular}

\section{DISCUSSION}

In this study, different procedures for sampling benthic invertebrates have been evaluated in terms of repeatibility among observers, precision and maximization of replication for a fixed amount of resources. As stated by other authors (Meese \& Tomich 1992), no approach is free of problems, and our results are consistent with this view. In particular, the performance of the procedures tested here changed from species to species, and the procedure most adequate for a given criterion did not necessarily meet the requirements of the others. Thus, the optimal strategy of sampling is a compromise between relative advantages and disadvantages. Results showed that: (1) there was a significant observer $x$ method interaction for Astroides calycularis, but although the rank of observers changed with method, the overall differences in the estimates of 
cover were similar; (2) divergence among observers was not constant from dive to dive for $A$. calycularis (observer $\times$ dive interaction) and also in relation to the method employed for Leptosammia pruvoti (observer $x$ method $x$ dive interaction); (3) the small quadrats were more precise than the large ones in determining the abundance of cnidarians irrespective of method. In contrast, precision depended upon the technique used to score the quadrats for Petrosia ficiformis, the small sampling units being more precise if used in conjunction with the visual method. Apparently, visual estimates from large quadrats were more precise than any other procedure to sample the cover of Geodia cydonium: $_{\text {in }}$ cost-benefit analyses allocated more resources to replication of areas rather than to plots per area, given the great variability occurring at the larger scale. The small quadrats in conjunction with the visual method provided the best procedure to maximize replication of areas given a fixed amount of resources.

Dethier et al. (1993) found the visual method more robust to bias due to observers than the point-intercept technique, when used to sample macroalgae in the intertidal. In contrast, Meese \& Tomich (1992) found greater variability among observers with the visual method in a similar environment. These differences have been discussed in terms of relative sensitivity of methods to variability in experience and training between observers. However, results are often inconclusive (e.g. Meese \& Tomich 1992), and comparisons between observers with different experience are confused with intrinsic differences among individuals (there must be replicate observers for each level of training to avoid this sort of confusion). This problem also occurred in the present study; therefore divergence among observers will not be discussed in terms of experience. However, it is worth noting that although divers changed their order of rank in relation to the method employed, only slight differences occurred. Further, variability due to observers in relation to some other factors (e.g. method or dives) was not observed for sponges. This may have come about because of the different size and spatial arrangement of sponges and cnidarians in the cave, the former being larger and less dispersed in quadrats than the latter. The visual method, as used in this study and in Dethier et al. (1993), is based on the mental grouping of organisms in subquadrats. If the size of the 'biological unit' being sampled is very small relative to the subquadrat, grouping may become problematic (also recognized by Dethier et al. 1993) and the procedure more prone to bias due to observers.

The results of this study also suggest that the performance of observers may be affected by environmental factors, as indicated by the significant interactions observer $x$ dive for Astroides calycularis and observer $x$ method $\times$ dive for Leptosammia pruvoti. Again, these interactions were not found for sponges, possibly because of their relatively large size. An additional problem with $A$. calycularis was that this species might have been confused with another cnidarian, Cariophyllia inornata, because of similarities in size, shape and colour (although A. calycularis is colonial and $C$. inornata is not). Differences among observers from dive to dive ranged from a minimum of $0.7 \%$ to a maximum of $14.3 \%$ for $A$. calycularis, and from 0.7 to $11 \%$ for $L$. pruvoti. These results suggest that local environmental factors that are likely to change through time (e.g. turbidity of the water, general conditions of the sea) may have important effects on the performance of a diver, also influencing his (her) psychological and emotional status. These factors are obviously interrelated and there is no reason to assume homogeneity across observers. Of course, training may reduce this variability. Logistic problems may also interfere with the sampling activity. For example, on 2 occasions the main source of light for a particular observer stopped working before the end of the dive. In this case, sampling was completed using a secondary, less powerful light. This may have increased the differences among observers, particularly for estimates of cover of small organisms (i.e. cnidarians).

Few studies have explicitly investigated the robustness of a given method of sampling to bias due to observers (e.g. Meese \& Tomich 1992, Dethier et al. 1993, Inglis \& Lincoln Smith 1995) and whether a given sampling program is completed by a single researcher or by a team is rarely reported in published papers. This study demonstrates that divergence among observers may change significantly in different environmental circumstances, and this might occur in other subtidal systems as well (e.g. kelp forests and seagrasses). This suggests caution in employing different researchers in the same sampling project, at least before this source of variation is accounted for. Although changes on the order of $10 \%$ may be unimportant in many cases, they may be critical if the size of the effect under investigation is small.

The size of the unit of sampling may have a strong effect on the precision of the estimates being collected (Elliot 1977, Southwood 1978, Dowing \& Anderson 1985, Dowing \& Cyr 1985, Morin 1985, Andrew \& Mapstone 1987). The concept of size here is relative to the scale of aggregation of the organisms. Variation among replicates is expected to be large when the size of the unit of sampling is close to the average distance among aggregations (Andrew \& Mapstone 1987). In contrast, estimates coming from large units are likely to be less affected by patterns in the spatial arrangement of populations (Elliot 1977, Southwood 1978, Green 1979). Surprisingly, the small quadrats gave more precise estimates of the cover of cnidarians than 
the large ones in this study. This result is counterintuitive and difficult to explain. Even more difficult is to explain why precision was affected interactively by size and method for Petrosia ficiformis. A potential explanation for cnidarians is offered by the results of the pilot study. Spatial variation in the distribution of organisms was very large among areas (Table 4), while variability within areas (i.e. among replicates) was low. This suggests that the scale of aggregation of organisms was large relative to the size of both units. Thus, sampling a plot of $50 \times 50 \mathrm{~cm}$ or a plot of $20 \times 20 \mathrm{~cm}$ made little difference with respect to the patterns of spatial arrangement of cnidarians. In contrast, differences in size might have been important with respect to the heterogeneity of the substratum. In general, the small quadrats fitted better than the large ones among the asperities of the substratum. In some cases the large quadrats were kept at a distance of 20 to $30 \mathrm{~cm}$ from the substratum because of the presence in the sampling area of a rock or a sponge (Geodia cydonium) protruding from the vault. In these circumstances an observer might have erroneously scored organisms well beyond the limits of the quadrat, because the surface perceived as the area of sampling was greater than the real one, the former being positively related to the distance between the quadrat and the substratum. Thus, the large units might have introduced a greater bias than the small ones, resulting in reduced precision and probably overstimating the abundance of organisms. This might also explain why estimates of the cover of Leptosammia pruvoti and P. ficiformis obtained with the large quadrats were significantly greater than those obtained with the small ones.

With regard to the question of which procedure provides the optimal strategy of sampling, overall results suggest the use of small quadrats in conjunction with the visual method is appropriate for all species but Geodia cydonium. This procedure should provide the best combination of precision and efficiency (cost of obtaining a given level of precision) for both cnidarians and Petrosia ficiformis, allowing maximization of replication of areas in future studies. The use of large quadrats sampled with the visual method is probably the best solution for $G$. cydonium, given the apparent greater precision of this procedure for the large sponge (Fig. 1). The disadvantage due to the lower repeatability associated with the visual method is considered irrelevant. Divergence among observers was very similar for the 2 methods, and it was very low with respect to the background of variation occurring in the system. In contrast, the effects due to variability in the response of observers to changing environmental conditions must be considered carefully in future studies, particularly if hypotheses about temporal variation are of concern.
Acknowledgements. We thank M. S. Foster and A. J. Underwood for critical comments on the manuscript. We also thank A. J. Underwood, M. G. Chapman and the participants in the course of experimental design held in Evora (Portugal) in May 1995, for stimulating discussion. This study was funded in part by the EC under MAST programme contract MAS2CT93-0058

\section{LITERATURE CITED}

Alvisi M, Barbieri F, Bruni R, Cinelli F, Colantoni P, Grandi GF, Maltoni P (1994) La Grotta Azzurra di capo Palınuro (Salerno). Mem Ist It Spel 2nd Ser 6:51-56

Andrew NL, Mapstone BD (1987) Sampling and the description of spatial pattern in marine ecology. Oceanogr Mar Biol A Rev 25:39-90

Balduzzi A, Pansini M, Pronzato R (1985) Estimation par relèvements photographiques de la distribution de spongiaires et bryozoaires dans un grotte sous-marine du Golfe de Naples. Rapp Comm Int Mer Médit 29:131-134

Cinellı F, Fresi E, Mazzella L, Pansini M, Pronzato R, Svoboda A (1977) Distribution of benthic phyto- and zoocoenoses along a light gradient in a superficial marine cave of the Sorrentine Peninsula. In: Keegan BF, Leidingh O, Boaden PJS (eds) Biology of benthic organisms. Pergamon. Press, London, p 173-184

Crowder MJ, Hand DJ (1990) Analysis of repeated measures. Chapman and Hall, London

Dayton PK (1975) Experimental studies of algal canopy interactions in a sea otter-dominated kelp community at Amchitka Island, Alaska. Fish Bull US 73:230-237

Dethier MN (1984) Disturbance and recovery in intertidal pools: maintenance of mosaic patterns. Ecol Monogr 54: $99-118$

Dethier MN, Graham ES, Cohen S, Tear LM (1993) Visual versus random-point percent cover estimations: 'objective' is not always better. Mar Ecol Prog Ser 110:9-18

Dowing JA, Anderson MR (1985) Estimating the standing biomass of aquatic macrophytes. Can J Fish Aquat Sci 42: $1860-1869$

Dowing JA, Cyr H (1985) Quantitative estimation of epiphytic invertebrate populations. Can J Fish Aquat Sci 42 : $1570-1579$

Elliot JM (1977) Some methods for the statistical analysis of samples of benthic invertebrates, 2 nd edn. Freshwater Biological Association, Ambleside

Foster MS, Harrold C, Hardin DD (1991) Point vs. photo quadrat estimates of the cover of sessile marine organisms. J Exp Mar Biol Ecol 146:193-203

Gili JM, Riera T, Zabala M (1986) Physical and biological gradients in a submarine cave on the Western Mediterranean coast. Mar Biol 90:291-297

Green RH (1979) Sampling design and statistical methods for environmental biologists. John Wiley \& Sons, New York

Greig-Smith P (1983) Quantitative plant ecology. University of California Press, Berkeley

Inglis GJ, Lincoln Smith MP (1995) An examination of observer bias as a source of error in surveys of seagrass shoots. Aust $J$ Ecol 20:273-281

Kennelly SJ, Underwood AJ (1984) Underwater microscope sampling of a sublittoral kelp community. J Exp Mar Biol Ecol 76:67-78

Kennelly SJ, Underwood AJ (1985) Sampling of small invertebrates of natural hard substrata in a sublittoral kelp forest. J Exp Mar Biol Ecol 89:55-67 
Leonard GH, Clark RP (1993) Point quadrat versus video transect estimates of the cover of benthic red algae. Mar Ecol Prog Ser 101:203-208

Littler MM, Littler DS (1985) Nondestructive sampling. In: Littler MM, Littler DS (eds) Handbook of phycological methods-field methods: macroalgae. Cambridge University Press, Cambridge, p 161-175

Meese RJ, Tomich PA (1992) Dots on the rocks: a comparison of percent cover estimation methods. J Exp Mar Biol Ecol 165:59-73

Morin A (1985) Variability of density estimates and the optimization of sampling programs for stream benthos. Can J Fish Aquat Sci 42:1530-1534

Roberts DE, Fitzhenry SR, Kennelly SJ (1994) Quantifying subtidal macrobenthic assemblages on hard substrata using a jump camera method. J Exp Mar Biol Ecol 177. $157-170$

This article was submitted to the editor
Snedecor GW, Cochran WG (1967) Statistical methods, 6th edn. Iowa State University Press, Ames

Southward AJ, Kennicutt MC, Alcalà-Herrera J, Abbiati M, Airoldi L, Cinelli F, Bianchi CN, Morri C, Southward EC (1996) On the biology of submarine caves with sulphur springs: appraisal of ${ }^{13} \mathrm{C} /{ }^{12} \mathrm{C}$ ratios as a guide to trophic relations. J Mar Biol Ass UK 76:265-285

Southwood TRE (1978) Ecological methods, 2nd edn. Chapman and Hall, New York

Underwood AJ (1981) Techniques of analysis of variance in experimental marine biology and ecology. Oceanogr Mar Biol A Rev 19:513-605

Whorff JS, Griffing L (1992) A video recording and analysis system used to sample intertidal communities. J Exp Mar Biol Ecol 160:1-12

Winer BJ (1971) Statistical principles in experimental designs, 2nd edn. McGraw-Hill Kogakusha, Tokyo

Manuscript first received: November 20, 1995

Revised version accepted: March 18, 1996 